\title{
Cellulose fiber-reinforced thermosetting composites: impact of cyanoethyl modification on mechanical, thermal and morphological properties
}

\author{
Md Rezaur Rahman ${ }^{1}$ (D) Sinin Hamdan ${ }^{1} \cdot$ Zainab Binti Ngaini $^{2}$. \\ Elammaran Jayamani ${ }^{3}$ - Akshay Kakar ${ }^{1}$ - Muhammad Khusairy Bin Bakri ${ }^{1,2}$. \\ Fahmi Asyadi Bin Md Yusof ${ }^{4}$
}

Received: 28 July 2018 / Revised: 4 October 2018 / Accepted: 2 November 2018 / Published online: 12 November 2018 (c) Springer-Verlag GmbH Germany, part of Springer Nature 2018

\begin{abstract}
This study explores the mechanical, thermal and morphological properties of untreated and cyanoethyl-treated kempas wood sawdust cellulose fiber-reinforced unsaturated polyester composites. The fiber loadings of the composites were varied from 0 to $20 \mathrm{wt} \%$, with the increment of $5 \mathrm{wt} \%$. The composites were tested for water absorption, and their FTIR spectroscopy, SEM and TGA results were analyzed. The FTIR results show that the fiber treatment reduces the hydroxyl groups in the cellulose, replacing them with the cyanoethyl groups. The TGA results show that the composites are stable up to $324{ }^{\circ} \mathrm{C}$. SEM images of the treated fiber composites showed that there were no visible gaps between fibers and matrix which indicates a strong interfacial bond. From the mechanical tests, $15 \mathrm{wt} \%$ fiber loading composite was strongest. Among all the composites, cyanoethyl cellulose fiber unsaturated polyester composites had the most desirable mechanical and thermal properties, whereas the fiber treatment showed the improvement of interfacial bonding.
\end{abstract}

\section{Abbreviations}

CECFUPC Cyanoethyl cellulose fiber unsaturated polyester composites

WF Wood fiber

WS Wood sawdust

Md Rezaur Rahman

rmrezaur@unimas.my

1 Faculty of Engineering, Universiti Malaysia Sarawak, Jalan Datuk Mohammad Musa, 94300 Kota Samarahan, Sarawak, Malaysia

2 Faculty of Resources Science and Technology, Universiti Malaysia Sarawak, Jalan Datuk Mohammad Musa, 94300 Kota Samarahan, Sarawak, Malaysia

3 Faculty of Engineering, Computing and Science, Swinburne University of Technology Sarawak Campus, Jalan Simpang Tiga, 93350 Kuching, Sarawak, Malaysia

4 Polymer Technology Section, Universiti Kuala Lumpur Malaysia - Institute of Chemical and Bioengineering Technology, 78000 Alor Gajah, Melaka, Malaysia 